\title{
Sensitivity of Treponema denticola Isolated From Infected Periodontal Pockets to Some Mouth Rinses and Common Antibiotic
}

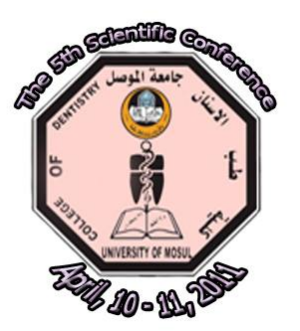

\section{ABSTRACT}

Aims: Treponema denticola is one of the most important periodontal pathogens because of its high lytic enzymatic activity leading to tooth lose and its ability to invade tissues and spread via blood stream causing systemic infections, this study coming to be the first local study concerning with this anaerobic fastidious bacterium and looking at the possibility of rely on the culturing methods in determining the most preferred chemotherapeutic drugs for limiting of bacterial activity and spread, as well as investigating the range of the antimicrobial activity of some mouth rinses and number of antibiotics. Materials and Methods: 139 samples were collected from periodontal pockets with a depth of $\geq 3 \mathrm{~mm}$ under supervision of specialist dentitist, then placed in a reduced transport medium. The activity and effective spectrum of different concentrations for three kinds of widely used mouth rinses in the treatment of periodontal infections including Biofresh $\mathrm{K}$, Biofresh $\mathrm{F}$ and Zak towards this bacterium was studied using sensitivity test methods, furthermore, the minimum inhibitory cocentration of antibiotics amoxillin, ciprofloxacin, clindamycin, azithromycin and mitronidazole was determined using antibiotic discs diffusion method. Results: The results showed that Biofresh $\mathrm{K}$ is the best in the term of bacterial killing as its inhibition activity continued to $1: 16$ dilution and when the sensitivity of T.denticola isolates to some antibiotics was tested, it was appeared that ciprofloxacin is the best causing growth inhibition with the lowest minimum inhibitory cocentration $(0.0001 \mathrm{mg})$, and when the synergistic effect of the tested antibiotics was studied it is becoming clear that the lowest antibiotic concentrations can cause growth inhibition when the two antibiotics (mitronidazole + ciprofloxacin) or (mitronidazole + amoxillin) are used in combination. Conclusions: It is possible to depend on culturing methods for determining the sensitivity of the bacterium T.denticola to chemotherapeutic drugs. Biofresh $\mathrm{K}$ is the best among the rinses under study and the antibiotic CIP is the best one with the lowest MIC and the lowest concentration of the antibiotics resulting in growth inhibition can be achieved when they are used in combination.
\end{abstract}

Asst Lect Summaya A. S. Muhammad (BSc, MSc); Asst Prof Dr.Amera M. M. Al-Rawi (BSc, $M S c, P h D)$

Department of Biology, Sciences College, Mosul University

Key Words: Systemic antibiotics against Treponema denticola, Local chemotherapy for the management of periodontitis. 


\section{INTRODUCTION}

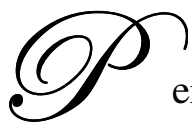

eriodontitis is considered as a polymicrobial mixed infection and it is one of the major oral diseases arising from the synergistic action of the polymicrobial population of endogenous bacteria which is called subgingival biofilm ${ }^{(1)}$.

Oral Treponema are normally exist in healthy gingival fluid and tissues as a normal flora at low numbers, but they are increased to reach $50 \%$ of the microbial community to contribute as an important member of the periodontal pathogens, and T.denticola was considered to be the most important one that isolated in frequency from periodontal infections because of its normal occurrence in the bacterial plaque of healthy cases, also it is considered as an indicator to the occurrence and progression of recurrent infections as it exhibit strong putative virulence factors like surface proteins, lytic enzymes and its unique motility in connective tissues, in addition to the bacteria's ability with its metabolic products or cell components to penetrate gingival connective tissues ${ }^{(2,3,4)}$.

It is possible to control plaque community to restrict the progression of oral infections such as caries, gingivitis and periodontitis by mechanical means with scaling and root planning(SRP), in addition to the using of local chemotherapeutic drugs and systemic antibiotics.

Several studies referred to the preference use of local chemotherapeutic drugs as it can diffuse to the pockets even in low dosage, also it can avoid the patient from many side effects of systemic antimicrobial agents, and these therapeutic compounds are commercially available in the form of rinses, gels, chips, fibers, dentifrices or iozenges and most of them contain antimicrobial agents ${ }^{(5,6,7)}$

Other studies praised the importance of using systemic antibiotics as they can reach via the serum to the infected sites of deep pockets that have not reached by SRP or local chemotherapeutic drugs ${ }^{(8)}$.

Several procedures have been applied to examine the efficiency of the antimicrobial agents against anaerobic periodontal pathogens in vitro, one of which through measuring the effectiveness of different concentrations of antibiotic discs by adding them to the liquid or semisolid media and monitoring growth inhibition ${ }^{(9)}$ or by adding different concentrations of the substance under study into the wells on the plate surface inoculated with the microorganism ${ }^{(10)}$ or adding different concentrations of the chemical substances to the melted solid media and after solidification the bacterial sample is cultured on $\mathrm{it}^{(11)}$ or by the E test method using a strip of graduated concentrations of antibiotic and place this strip on the culture plate ${ }^{(12)}$ while other researcher investigated the efficiency of mechanical methods(SRP) and chemotherapeutic drugs in vivo by examining subgingival pocket samples before and after treatment ${ }^{(13)}$.

\section{MATERIALS AND METHODS}

Culture Media: The New Oral Spirochetes(NOS) medium (12.5 g Brain heart infusion, $10.0 \mathrm{~g}$ Trypticase, $12.5 \mathrm{~g}$ Yeast extract, $0.5 \mathrm{~g}$ Sodium thioglycolate, $1.0 \mathrm{~g}$ L-Cysteine, $0.25 \mathrm{~g}$ LAspartate, $2.0 \mathrm{~g}$ Glucose, $0.006 \mathrm{~g}$ Ascorbic acid, 2.0g Sodium bicarbonate, 1 litter distelled water) and Thioglycolate_ BHI agar(3 parts thioglycolate medium, 1 part BHI, $7 \mathrm{~g}$ agar ) were prepared as previously described ${ }^{(14)}$

Samples: patients affected with periodontitis attending the Teaching Hospital of the Dentistry College in Mosul university and Right Sided River Center of Dentistry were collected for the period from 3/11/2008 to 8/6/2009. 139 samples from periodontal pockets with a depth $\geq 3 \mathrm{~mm}$ were collected following the steps outlined by ${ }^{(15)}$ and under the supervision of a specialist 
dentitists then placed in a reduced transport media ${ }^{(16)}$.

$0.1 \mathrm{ml}$ of the transport media was inoculated into NOS medium and incubated along with a tube containing anaerobic indicator (Resazurin) under optimum anaerobic condition $(80 \% \mathrm{~N} 2$ and $10 \% \mathrm{CO}_{2}$ ) in anaerobic jar at $377^{\circ} \mathrm{C}$ for 5 days. After growth displaying it was cultured into Thioglycolate_BHI agar, then the morphological and biochemical identification tests specialized for T.denticola were done as described by ${ }^{(17)}$.

Studying the Effect of Some Mouth Rinses on T .denticola: The effectiveness and spectrum effect of some kinds of oral rinses upon $T$. denticola was studied by testing the bacterial sensitivity to various concentrations of three oral rinses widely used in the treatment of periodontal infection including:

- Biofresh K (0.12\% Chlorhexidine(gluconate)): Syrian origin with distinction from Kamifluor French Company.

- Biofresh F(0.137\%Sodium monofluorophosphate, Sodium fluoride): Syrian origin with distinction from Kamifluor French Company.

- Zak $(0.12 \%$ Chlorhexidine digluconate, $0.05 \%$ Sodium fluoride): Syrian origin.

- The procedure applied by ${ }^{(10)}$ was followed as bellow:

- Bacterial suspension in a normal saline was prepared and compared with MacFerland tube 0.5 .

- Ten fold dilutions to the extent 1:1000 and tow fold dilutions to the extent 1:64 from each kind of the rinses were made.

- $0.1 \mathrm{ml}$ of the bacterial suspension was spread on the surface of Thioglycolate_ BHI agar containing $0.7 \%$ agar.

- Wells on the agar surface were made with $10 \mathrm{~mm}$ diameter using clean sterilized open sides test tube measuring $10 \mathrm{~mm}$.

- $0.1 \mathrm{ml}$ of each dilution was added to one of the wells and then the plates were incubated anaerobically at $37^{\circ} \mathrm{C}$ for 5 days.

- The inhibition zone diameter greater than $2 \mathrm{~mm}$ was measured by subtraction the well diameter (10) from the total inhibition zone, and photographed by digital camera.

Sensitivity of $T$. denticola to Some Antibiotics: Some antibiotics used in the management of periodontal infections were investigated by determining the minimum inhibitory concentration(MIC) relying the disc method described by ${ }^{(9)}$ as a two fold dilutions of the antibiotics were prepared and added to filter paper discs(NO.1) and then distributed on the surface of the medium inoculated with the bacterium.

\section{- Preparation of the Antibiotic Dilutions:}

- The antibiotics powder from the origin illustrated in Table(1) with the solvent and dilution solution were used as it was mentioned by Wikler et al., ${ }^{(18)}$.

- After the antibiotics were dissolved by $500 \mathrm{mg}$ of each one, $0.1 \mathrm{ml}$ from each dilution was added to 100 pre-sterilized filter paper discs _by autoclave_ and then dried in the oven at 40․

- Preparation of the bacterial suspension: Colonies aging 75 hours growing on the Thioglycolate_BHI agar was selected to make bacterial suspension in the normal saline and compared with MacFerland tube 0.5 as mentioned by Andrews, ${ }^{(11)}$.

\section{- Test Performance:}

$-0.1 \mathrm{ml}$ of the bacterial suspension was spread on the Thioglycolate_BHI agar . 
-The antibiotic discs were added using sterile forceps and incubated in the optimum conditions.

-The inhibition zones were observed after 3 days of incubation, their diameters were measured and the MIC for each antibiotic was determined as the lowest concentration causing no growth.

Table(1) The Antibiotics Used in This Study

\begin{tabular}{llll}
\hline Antibiotics & Origin & Solvent solution & Dilution Solution \\
\hline Amoxillin (AM) & Asia Pharma & PBS (pH=6) & PBS (pH=6) \\
Ciprofloxacin (CIP) & Ajanta Pharma & Distilled water & Distilled water \\
Clindamycin (CL) & Dar Al-Dawa & Distilled water & Distilled water \\
Azithromycin (AZ) & Riua Pharma & 95\%Ethyl alcohol & Distilled water \\
Mitronidazole (MT) & Barakat & Dimethyl sulfoxide & Distilled water
\end{tabular}

(DMSO)

\section{- Preparation of the MacFerland Tube 0.5:}

$-0.048 \mathrm{M}$ of $\mathrm{BaCl}_{2}$ solution was prepared by dissolving $1.17 \%$ (w/v) of $\mathrm{BaCl}_{2} .2 \mathrm{H}_{2} \mathrm{O}$.

$-0.18 \mathrm{~m}$ of $\mathrm{H}_{2} \mathrm{SO}_{4}(1 \% \mathrm{v} / \mathrm{v})$ was prepared.

$-0.5 \mathrm{ml}$ of $\mathrm{BaCl}_{2}$ solution was added to $99.5 \mathrm{ml}$ of $\mathrm{H}_{2} \mathrm{SO}_{4}$, well mixed and stored in the refrigerator.

\section{RESULTS AND DISCUSSION}

T.denticola appeared as brown helical cells by Fontana stain (Figure 1) and their lived helical twisted cells were seen actively motile when examined under phase contrast microscope(figure2). In our study we could isolate T.denticola in 93(66.9\%) while 46(33.1\%) samples were negative. All T.denticola isolates show negative activity to catalase, lipase and nitrate reductase enzymes and carbohydrates fermentation, but positive activity to gelatinase, protease and phospholipase $\mathrm{C}$ enzymes and motility test, indol and $\mathrm{H}_{2} \mathrm{~S}$ production and esculin hydrolysis, these results are in conformity to that outlined by(محمد) ${ }^{(17)}$.

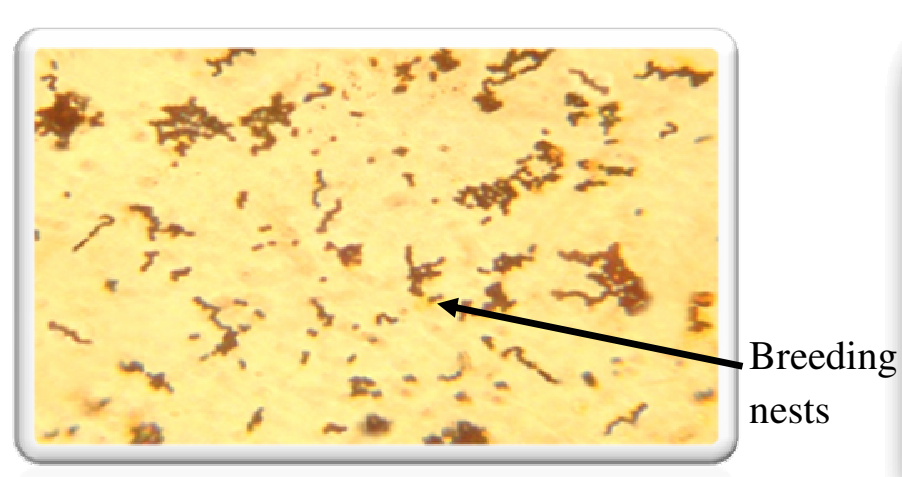

1000X magnification

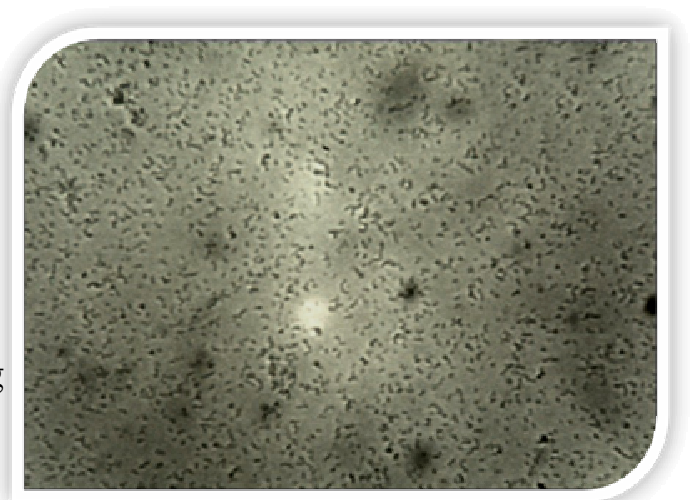

Figure (2) Treponema cells under phase contrast microscope by $400 \mathrm{X}$ magnification 
The Effect of Some Mouth Rinses on T.denticola: When the effectiveness of the three widely used rinses was tested it was appeared that Biofresh $\mathrm{K}$ is the best one as its inhibitory effect continued until 1:16 dilution(Figure 3) followed by Zak 1:8 and while Biofresh F showed its effect just in the net concentration, other isolates withstood it.

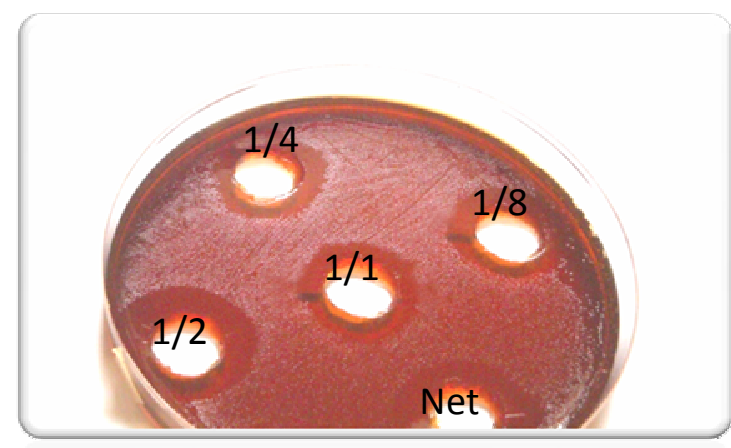

Figure (3) Inhibitory effect of

Biofresh $\mathrm{K}$ dilutions upon $T$. denticola

on Thioglycolate-BHI Agar

The active ingredient of Biofresh $\mathrm{K}$ is chlorhexidine(cataionic bibisguanide) and the principle of its action is by attaching negative charge on the bacterial surface and extracellular components causing osmolitical unbalance via disturbing cell membrane functions, and its effect is higher under alkaline $\mathrm{pH}$ than acidic $\mathrm{pH}$ and decreases in the presence of some organic substances that is a problem when used in the infected subgingival areas that contain high levels of serum proteins. This compound is abroad spectrum against Gram positive and negative bacteria, Fungi and Yeast and it is active against many of oral pathogens including periodontal pathogens like T.denticola, Popheromonas gingivalis and Actinobacillus actinomycecomitance ${ }^{(8,19)}$ and it acts as a bacteriostatic at a low concentrations by releasing low molecular weight molecules e.g. phosphorus, potassium from the bacterial cell, but at higher concentrations it acts as a bactericidal by coaggulating cytoplasmic components leading to bacterial cell killing, therefore it is an active therapy for the treatment of periodontal infections since it can reduce gingival tissues inflammation, sulcus bleeding and pocket depth especially after SRP for chronic periodontitis, also it can reduce the accumulation of bacterial plaque through its instantly bactericidal action as well as its long term bacteriostatic action as it can be absorbed to the pellicles on the enamel and binding to the carboxyl group of mucin layer and it can readily release from it by exchanging with calcium ions excreted from salivary glands, so several previous studies concluded the significant reduction in the level of oral pathogens T.denticola and Bacteriods forsythus by using chlorhexidine ${ }^{(20)}$.

The fluoride compounds of Biofresh $\mathrm{F}$ reduce inflammatory cytokines in the chronic infections and the fluoride ion has no effect against the development of bacterial plaque and gingivitis, but fluoride salts somewhat provides activity against bacterial plaque especially when the effect comes from the non-fluoride portion, nevertheless, fluoride compounds generally have less effect than chlorhixidine ${ }^{(21,22)}$.

Sensitivity to Antibiotics: The results of the sensitivity of $T$. denticola to some antibiotics either in single use or in combination in the term of MIC are listed in (Table 2 and Figure 4, 5) Because of Spirochetes can rapidly grow well in the semisolid media and it is possible to see the 
growth during three days of incubation, so the addition of antibiotic discs to the media provides a quick technique to determine the sensitivity of these bacteria to antibiotics, furthermore, this method is preferred to the tedious tube dilution technique using in Treponemal sensitivity test, and according to the antibiotic discs method this bacteria considered to be sensitive to that antibiotic when no growth occur after three days of incubation ${ }^{(9)}$. The chose of the preferred antibiotic is one of the key role in the management of periodontal infections depending on the suitable bacteriological analysis, so the culturing techniques are necessary for determining the bacterial sensitivity to the antibiotics ${ }^{(23)}$.

Table (2) The Minimum Inhibitory Concentration of the Antibiotics on T.denticola

\begin{tabular}{ll}
\hline Antibiotics & MIC(mg/disc) \\
\hline Amoxillin(AM) & 0.0007 \\
Ciprofloxacin(CIP) & 0.0001 \\
Clindamycin(CL) & 0.0009 \\
Azithromycin(AZ) & 0.001 \\
Mitronidazole(MT) & 0.001 \\
AM/MT & $0.00004 / 0.0001$ \\
CIP/MT & $0.000006 / 0.00005$
\end{tabular}

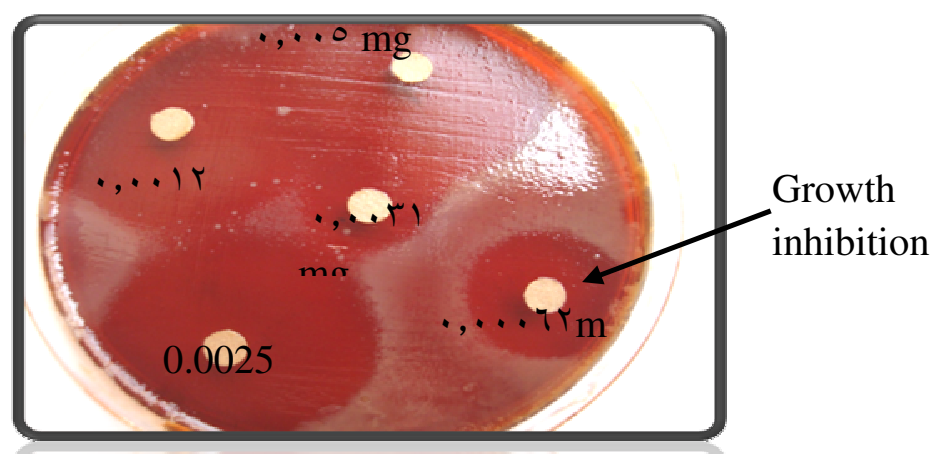

Figure (4) the inhibitory effect of the Ciprofloxacin MICs towards T. denticola

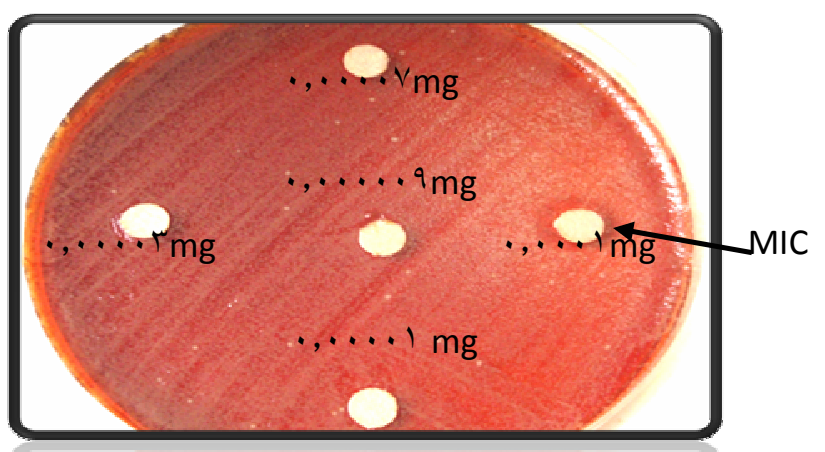

Figure (5) the effect of the $0.0001 \mathrm{mg}$ of Ciprofloxacin on the growth of $T$. denticola

The results showed that the best antibiotic resulting in growth inhibition with the single use is $\mathrm{CIP}(\mathrm{MIC}=0.0001 \mathrm{mg} / \mathrm{disc})$ followed by $\mathrm{AM} \quad(\mathrm{MIC}=0.0007 \mathrm{mg} / \mathrm{disc}$ ) while the MIC concentration of MT was $0.001 \mathrm{mg} / \mathrm{disc}$ alone, its activity continued to $0.00005 \mathrm{mg} / \mathrm{disc}$ in combination with $0.000006 \mathrm{mg} / \mathrm{disc}$ of CIP and to $0.0001 \mathrm{mg} /$ disc in combination with $0.00004 \mathrm{mg} / \mathrm{disc}$ of AM.

Ciprofloxacin belongs to the second generation Fluorquinolones of Quinolones after the addition of fluorin to the six position of the main Quinolones ring to enhance its antimicrobial activity. The mechanism of action of these antibiotics is by inhibition the enzyme DNA gyrase that helps the unwinding of the supercoiling of DNA strands at the replication fork, and Topoisomerase enzyme that contribute in the untwisting of the supercoiling and separate the newly DNA strands after replication; as a result the bacterial nucleic acids replication is stopped. 
These antibiotics don't affect the host cell enzymes. These antibiotics are active against Gram negative rods including the facultative or obligate anaerobic putative periodontal pathogens and are used in the treatment of periodontal superinfection ,but it is inactive against Strepotococci persisting in the subgingival areas.

The antibiotic Amoxillin is a semisynthetic pencillin and it is a broad spectrum against periodontal pathogens and active in the treatment of $\mathrm{AggP}$ in the concentration of about $500 \mathrm{mg}$ as it is readily well absorbed after oral dose and most time used with MT.

Aziyhromycin belongs the macrolides antibiotics, broad spectrum and active in the treatment of $\mathrm{CP}$ and AggP infections by inhibiting bacterial protein synthesis and there is an evidence that it can penetrate into the fibroblast and macrophages in a concentration 100-200 time greater than its concentration in the extracellular matrix and when the macrophages are migrate to the infected sites and rupture during phagocytosis large amount of this antibiotic will release from the cells.

Clindamycin is a pyranoside, broad spectrum especially against anaerobic Gram negative and positive bacteria but it is inactive against aerobic Gram negative bacteria, it can stop clinical attachment lose and it is an active drug if the patient is suffering from pencillin allergy or not responding to Tetracycllin therapy.

Metronidazole is a synthetic Nitromidazole and its inhibitory effect is a bactericidal upon anaerobes specially Gram negative rods and because of the sensitivity of Spirochetes to this antibiotic, it is an active drug in the treatment of periodontal infections. As the antibiotic molecule enter inside the bacterial cell, it will activated by reduction to an intermediate product which is responsible for the antibacterial activity by ingestion of bacterial DNA, and this intermediate product has a short-life period that is quickly disconnected into an inactive nontoxic end product. This antibiotic is active only against anaerobic bacteria which can provide the low reduction- potential needed for the reduction of the antibiotic molecule into an active compound, so it is the drug of choice especially when used with other antibiotics ${ }^{(22,24,25)}$.

Since periodontitis is often arise from the action of more than one pathogen, so the consequent use of more than one antibiotic had receive a great attention as it increases the spectrum of antimicrobial effect of the antibiotics and prevents the possibility of the development of bacterial resistance to the single antibiotic. Among this useful sets which had prove its success is the combination between MT_AM at a concentration of $250-375 \mathrm{mg} 3$ times daily for 8 days or MT_CIP at a concentration of $500 \mathrm{mg}$ twice daily for 8 days. In addition to, the perfect manner to combat periodontal pathogens is the combination between the mechanical methods and chemotherapeutic drugs, also the correct use of antibiotics and washing the gingiva with $10 \%$ povidon_iodine(by the dentitists) and $0.1 \%$ Sodium Hypochlorite(by the patient) and the use of $0.12-0.2 \%$ Chlorhixidine is an inexpensive, safety and active antimicrobial dose ${ }^{(8)}$.

\section{REFERENCES}

1. Sakamoto M., Huang Y.,Ohnishi M., Umeda M.,Ishikawa I., Benno Y. Change in oral microbial profile after periodontal treatment as determined by molecular analysis of 16SrRNA gene. J Med Microbiol. 2004;53:563-571.

2. Foschi F., Izard J., Sasaki H., Sambri V., Prati C., Muller R., Stashenko P. Treponema denticola in disseminating endocarditic infection. J Dent Res. 2006; 85(8): 761-765.

3. Riviere G.R., Derouen T. A., Kay S.L., Avera S.P., Stouffer V. K., Hawkins N. A.Association of oral spirochetes from sites of perioidontal health with development of periodontitis. J. Periodontol. 1997;68:1210-1214.

4. Walker S. G., Ebersole W. J., Holt S.C. Identification, isolation, and characterization of the 42-kilodalton major outer membrane protein (MomP) from Treponema pectinovorum ATCC33768. J Bacteriol. 1997;179(20): 64416447. 
5. Krespi Y. p., Shrime M. G., Kacker A.The relationship between oral malodor and volatile sulfur compoundproducing bacteria. Otolaryngology-Head and Neck Surgery. 2006;135(5): 671-676.

6. Lee S-H., Choi B-K.Antibacterial effect of electrolyzed water on oral bacteria. J. Microbiol. 2006;44(4):417-422.

7. Koshy G., Corbet E., Ishikawa I.A fullmouth disinfection approach to nonsurgical periodontal therapy-prevention of infection from bacterial reservoirs. Periodontol. 2004;36:166-178.

8. Slots J.Selection of antimicrobial agent in periodontal therapy. J. Perio. Res. 2002; 37: 389-398.

9. Abramson I. J., Smibert R. M.Methods of testing antibiotic sensitivity of spirochetes using antibiotic discs.Brit.J. Vener. Dis. 1972;48;269- 273.

10. Bretz W. A., Salvador S.L.Antimicrobial action of AXOL on periodontopathic bacteria. Braz. Dent. J. 1993;4(1): 49-52.

11. Andrews J. M. Determination of minimum inhibitory concentration. J. Ant. Chem. 2001;48: 5-16.

12. Kulik E.M., Leneit K., Chenacix S., Meyer J. Antimicrobial succeptibility of periodontopathogenic bacteria.J.Anti. Chemo. 2008; 61(5):1087-1091.

13. Vergani S. A., Silva E. B., Vinholis A. H. Systematic use of metonidazole in the treatment of Chronic periodontitis: a pilot study using clinical, microbiology, and enzymatic evaluation . Braz. Oral Res 2004;18(2):121-127.

14. Edwards A. M., Dymock D., Woodward M. J., Jenkinson H. F.Genetic relatedness and phenotypic characteristics of Treponema denticola associated with human periodontal tissues and ruminant foot disease. Microbiol. 2003; 149: 1083-1093.

15. Kasuga Y., Ishihara K., Okuda K. Significant detection of Porphyromonas gingivalis, B. forsythus and Treponema denticola in periodontal pocket. Bull Tukyo dent Coll. 2000;41(3):109-117.

16. Umeda M., Ishikawa I., Benno Y., Mistouka T.Improved detection of oral spirochetes with an anaerobic culture methods. Oral Microbiol Immunol. 1990 ;5:90-94.

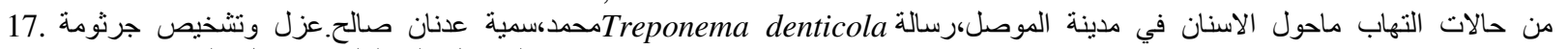

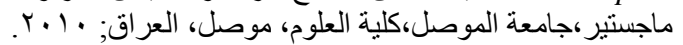

18. Wikler M.A., Cockerill F. R., Craige W.A., Dudley M. N., Eliopoulos G.M., Hecht D.W., Hindler J.F., Low D.E., Sheldon A.T., Tenover F.C., Testa R.T, Turnidge J.D., Weinstein M.P..Performance standard for antimicrobial susceptibility testing:fourteenth information supplement.vol.24, No.1, NCCLs. 2004

19. Grenier D.Reduction of proteolytic degradation by chlorhexidine. J Dent Res. 1993; 72(3): 630-633.

20. Silla M. P., Montiel- Company J. M., Almerich- Silla J. M.Use of chlorhexidine varnishes in preventing and treating periodontal disease . Areview of the literature. Med Oral Pathol Oral Cir Bucall. 2008;13(4): E257-E260.

21. Lindhe J., Karring T., Lang N. P."Clinical Periodontology and Implanlat Dentistry". $4^{\text {th }}$ ed.Blackwell Munksgaard. Parris. France. 2003.

22. Newman M.G., Takein H. H., Carranza F. A."CARRANZAs Clinical Periodontology". $9^{\text {th }}$ ed. W. B. Saunders Company.London. 2002.

23. Baehni P. C., Guggenhein B. Potential of diagnostic microbiology for treatment and prognosis of dental caries and periodontal disease. Crit Rev Oral Biol Med. 1996;7(3): 259-277.

24. Goering R.V., Dockrell H.M., Wakelin D., Zuckerman M., Chiodini P. L., Roitt I. M., Mims, C."Medical Microbiology". $4^{\text {th }}$ ed. Mosby.China. 2008.

25. Aurer A., Plancak D.Antimicrobial treatment of periodontal disease. Acta Stomatol Croat. 2004;38(1): 67-72. 